\title{
Inhibition by lipid A-specific monoclonal antibodies of priming of human polymorphonuclear leucocytes by endotoxin
}

\author{
J. J. CORNELISSEN, C.P. M. VAN KESSEL*, E. BROUWER*, C. A. KRAAIJEVELD* and J. VERHOEF* \\ Department of Internal Medicine and "Eijkman-Winkler Laboratory of Medical Microbiology, University Hospital \\ Utrecht, PO Box 85500, 3508 GA Utrecht, The Netherlands
}

\begin{abstract}
Summary. Exposure to lipopolysaccharide (LPS) primes polymorphonuclear leucocytes (PMNL) for enhanced release of oxygen metabolites after subsequent stimulation. The metabolic response of human PMNL primed with LPS and stimulated with formylmethionyl-leucyl-phenylalanine (FMLP) was measured by chemiluminescence (CL) as a parameter for endotoxic activity. Polymyxin B (PMB) and monoclonal antibodies (MAbs) with specificity for lipid A were tested for inhibition of the priming effect of Re LPS of Salmonella minnesota R595, Rc LPS of Escherichia coli J5 and smooth LPS of E. coli O111. The CL response of PMNL primed with Re LPS or Rc LPS was higher than that of PMNL primed with smooth LPS. Pre-incubation of rough or smooth LPS with PMB caused dosedependent inhibition of priming of PMNL. Two IgM MAbs, 8-2 and 26-20, which recognise different epitopes on the hydrophobic part of lipid A, also completely prevented priming of PMNL by either rough or smooth LPS. The dose-dependent inhibitory effect of both MAbs was similar to the inhibition by PMB. These results indicate that the binding of MAbs to the hydrophobic part of lipid A is important in blocking lipid A-mediated effects.
\end{abstract}

\section{Introduction}

It is now firmly believed that the pathophysiological features of gram-negative septic shock are caused by lipopolysaccharide (LPS, endotoxin). ${ }^{1}$ The lipid A structure, which is highly conserved among different gram-negative bacilli, is believed to be the toxic principle of endotoxin. ${ }^{2}$ Antibodies directed against the lipid A core-oligosaccharide part of LPS may show cross-reactivity with LPS from various gram-negative bacilli. ${ }^{3-5}$ There is some evidence that these antibodies may protect against gram-negative septicaemia, ${ }^{6-8}$ although conflicting results have been reported. ${ }^{9}$

We have produced several monoclonal antibodies (MAbs) directed against the 2-keto-3-desoxyoctulosonic acid (KDO)/lipid A inner core structure of LPS. ${ }^{10}$ Two IgM MAbs, 8-2 and 26-20, bind to different epitopes within the lipid A region. ${ }^{10,11}$ Both MAbs showed broad cross-reactivity with heterologous LPS preparations. In the present study the capacities of MAb 8-2 and 26-20 to inhibit LPS activity were tested in vitro with human polymorphonuclear leucocytes (PMNL) as targets. The exposure of PMNL to endotoxin in vitro primes the cells to respond to subsequent stimulation by enhanced release of oxygen metabolites and elastase secretion. ${ }^{12-14}$ This metabolic response of PMNL, the so-called respiratory burst, produces chemiluminescence, which can be amplified and measured in vitro by the addition of

Received 14 June 1990; accepted 17 Sep. 1990. luminol. ${ }^{15}$ PMNL primed by LPS in vivo may even exhibit an increased resistance to infection. ${ }^{16}$ However, this priming may also result in increased oxidative tissue damage, as in conditions such as the adult respiratory distress syndrome associated with septic shock. ${ }^{17}$

We used LPS-primed PMNL chemiluminescence as a parameter for endotoxic activity. It was examined whether priming of PMNL could be blocked by preincubating LPS with either MAb 26-20 or MAb 8-2. The inhibitory effect of both MAbs was compared with the well-known inhibitor polymyxin B (PMB), an antibiotic with potent anti-endotoxin activity. ${ }^{18}$

\section{Materials and methods}

\section{LPS preparations}

Three LPS preparations were used: Re LPS of Salmonella minnesota R595, which contains lipid A and the KDO molecule; Rc LPS of Escherichia coli J5, which contains the KDO/lipid A portion and part of the core oligosaccharide; and smooth LPS of $E$. coli O111:B4. Smooth LPS contains about 10-fold (w/w) less lipid A than rough LPS. Therefore, in our experiments, $1 \mu \mathrm{g}$ of smooth LPS was considered to be equivalent to $100 \mathrm{ng}$ of rough LPS. Re LPS of $S$. minnesota R595 and Rc LPS of $E$. coli J 5 were extracted by the phenol-chloroform-petroleum ether method as described by Galanos et al. ${ }^{19}$ LPS of E. coli 0111 was 
extracted and purified, as described previously, with hot phenol-water and sequential ultracentrifugation. ${ }^{20}$ Lyophilised LPS was dissolved in pyrogen-free water at $1 \mathrm{mg} / \mathrm{ml}$, sonicated and kept at $-20^{\circ} \mathrm{C}$. Before each test, LPS was freshly diluted in pyrogen-free phosphate-buffered saline (PBS), sonicated again for 3 min, and the $\mathrm{pH}$ was adjusted to 7.0 with triethylamine.

\section{Monoclonal antibodies}

The production and characterisation of IgM MAbs 8-2 and 26-20 were described previously. ${ }^{10}$ The MAbs were produced by hybridomas of BALB/c mice spleen cells and the mouse myeloma cell line Sp2/o-Ag14. MAb 8-2 was induced by the $\operatorname{Re}$ mutant of $S$. typhimurium and MAb 26-20 by synthetic lipid A. A Semliki Forest virus-specific IgM MAb (UM 8.4) was used as control. ${ }^{21}$

MAbs 8-2 and 26-20 and the control IgM MAbs were purified from mouse ascitic fluids by sizeexclusion chromatography, ${ }^{22}$ through a Sephacryl S300 column (Pharmacia, Uppsala, Sweden). IgMpositive peak fractions were estimated to be $>90 \%$ pure by chromatography and sodium dodecyl sulphatepolyacrylamide gel electrophoresis (SDS-PAGE). The protein concentration was measured by the method of Lowry et $a .^{23}$

\section{Isolation of PMNL}

Heparinised venous blood was obtained from healthy donors. PMNL were purified to $>97 \%$ purity by dextran sedimentation followed by Ficoll-Paque (Pharmacia) gradient centrifugation. Residual erythrocytes were lysed by hypotonic shock and PMNL were washed and resuspended in pyrogen-free PBS.

\section{Chemiluminescence of PMNL primed with LPS}

Primed PMNL were obtained by mixing $5 \times 10^{6}$ cells with either $100 \mathrm{ng}$ of rough LPS or $1 \mu \mathrm{g}$ of smooth LPS in $900 \mu$ l of pyrogen-free PBS for $60 \mathrm{~min}$ at $37^{\circ} \mathrm{C}$. Luminol $(50 \mu \mathrm{l})$ was added to the cell suspension to a final concentration of $10^{-5} \mathrm{M}$. PMNL were stimulated with $10^{-6} \mathrm{M}$ formyl-methionyl-leucyl-phenylalanine (FMLP) in a total volume of $1 \mathrm{ml}$. FMLP was dissolved in dimethylsulphoxide (DMSO) and stored at $-20^{\circ} \mathrm{C}$. Before use, this stock was diluted in pyrogen-free PBS. Immediately after adding FMLP, chemiluminescence (CL) was measured every $10 \mathrm{~s}$ for $3 \mathrm{~min}$ in a luminometer (Packard Instruments, Brussels, Belgium) at $37^{\circ} \mathrm{C}$. Inhibition experiments were performed by preincubation of $100 \mathrm{ng}$ of LPS with $10 \mu \mathrm{g}$ of MAb or $1 \mu \mathrm{g}$ of PMB (Sigma) in $110 \mu \mathrm{l}$ of pyrogen-free PBS for $30 \mathrm{~min}$ at $37^{\circ} \mathrm{C}$. Subsequently, PMNL were primed for $60 \mathrm{~min}$ with these mixtures and $C L$ was measured after addition of FMLP.

\section{Limulus amoebocyte lysate assay}

All reagents used were diluted in pyrogen-free PBS and tested for LPS contamination by the kinetic turbidimetric Limulus Amoebocyte Lysate (LAL) assay. ${ }^{24}$ The LAL used for this study was lot 99-01347 (Associates of Cape Cod, Inc.) and the LAL-5000 (Pyrotell/Benthos, Inc.) was used to read the test. All reagents contained less than $300 \mathrm{pg}$ of LPS $/ \mathrm{ml}$.

\section{Results}

\section{Chemiluminescence of PMNL primed with LPS}

Priming of human PMNL $\left(5 \times 10^{6}\right)$ with $100 \mathrm{ng}$ of LPS in $1 \mathrm{ml}$ of pyrogen-free PBS for $60 \mathrm{~min}$ at $37^{\circ} \mathrm{C}$ resulted in a clearly enhanced $C L$ response after subsequent stimulation with FMLP $\left(10^{-6} \mathrm{M}\right)$ when compared with PMNL pre-incubated with buffer only. Different LPS preparations were tested for their ability to prime PMNL for an enhanced CL response. PMNL were primed with $\operatorname{Re}$ LPS of $S$. minnesota $\mathrm{R} 595$ $(100 \mathrm{ng} / \mathrm{ml})$, Rc LPS of $E$. coli J5 $(100 \mathrm{ng} / \mathrm{ml})$ or smooth LPS of $E$. coli $\mathrm{O} 111(1 \mu \mathrm{g} / \mathrm{ml})$. As shown in the table and fig. 1, both smooth and rough LPS preparations primed PMNL, although the magnitude of the response depended on the kind of LPS used. Priming of PMNL with smooth LPS of $E$. coli 0111 produced peak values of CL two to three times higher than peak values produced by control PMNL incubated with pyrogen-free PBS. Priming with Rc LPS of E. coli J5 or Re LPS of $S$. minnesota R595 was more effective and generated higher peak values than priming with smooth LPS. The ratio of CL peak values produced by PMNL primed with rough LPS and control PMNL incubated with pyrogen-free PBS varied from four to 20. Furthermore, the priming effect of LPS on PMNL varied from donor to donor (table).

\section{Inhibition of enhanced chemiluminescence by polymyxin $B$}

Incubation of LPS (100 ng) with PMB (1 $\mu \mathrm{g})$ before

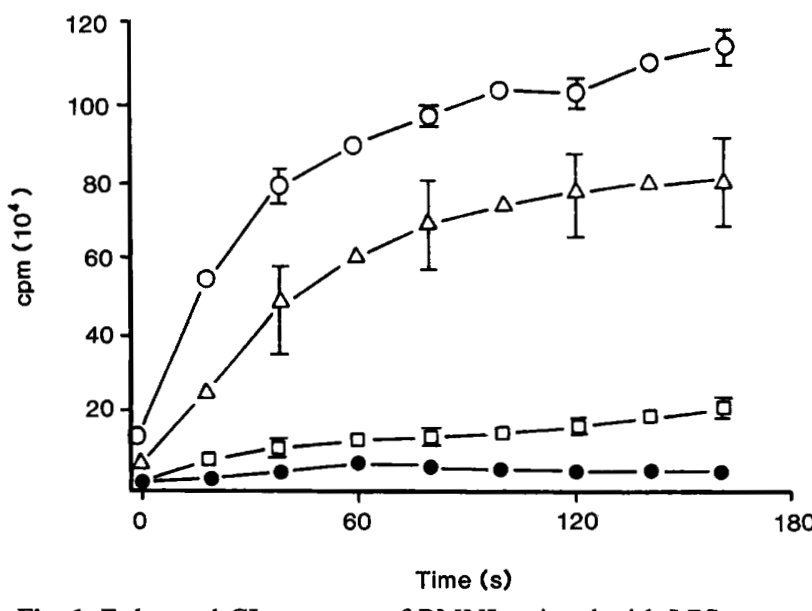

Fig. 1. Enhanced CL response of PMNL primed with LPS; mean values $(n=2)$ and range of variation of CL of PMNL from one donor primed with LPS of $E$. coli O111 ( $\square)$, Rc LPS of $E$. coli J5 $(\triangle), \operatorname{Re}$ LPS of $S$. minnesota $(O)$, and pyrogen-free PBS (O), followed by stimulation with FMLP. 
Table. CL of human PMNL from three donors primed by different LPS forms and stimulated with FMLP

\begin{tabular}{c|cccl}
\hline & \multicolumn{4}{|c}{$\begin{array}{c}\text { Mean }(\mathrm{n}=2) \text { CL peak values* } \\
\text { after priming with }\end{array}$} \\
\cline { 2 - 5 } Donor & PBS & Re LPS & J5 LPS & O111 LPS \\
\hline 1 & $50(2)$ & $1148(34)$ & $801(120)$ & $213(2)$ \\
2 & $52(12)$ & $186(25)$ & $144(2)$ & $113(18)$ \\
3 & $69(25)$ & $1284(53)$ & $838(216)$ & $324(1)$ \\
\hline
\end{tabular}

* Results are expressed as mean peak values (range of variation).

priming PMNL abolished the enhanced CL response after FMLP stimulation. The inhibitory effect of PMB was dose dependent, as shown in fig. 2 for priming with Rc LPS of $E$. coli J5. Complete inhibition of the priming effect of $100 \mathrm{ng}$ of LPS was obtained with $1 \mu \mathrm{g}$ of PMB; inhibition reduced sequentially when LPS was pre-incubated with $10^{-4}, 10^{-5}$, and $10^{-6} \mathrm{mg}$ of PMB respectively, in $100 \mu 1$ of PBS.

\section{Inhibition of enhanced chemiluminescence by $M A b s$ 8-2 and 26-20}

To establish whether MAbs directed against lipid A prevent LPS priming of PMNL, the three LPS preparations (100 $\mathrm{ng}$ ) were pre-incubated with either MAb 8-2 $(10 \mu \mathrm{g})$ or MAb 26-20 $(10 \mu \mathrm{g})$ in $110 \mu \mathrm{l}$ of pyrogen-free PBS for $30 \mathrm{~min}$ at $37^{\circ} \mathrm{C}$. Pre-incubation with either MAb completely prevented the priming of PMNL by $\operatorname{Re}$ LPS of $S$. minnesota R595 (fig. 3A), Rc LPS of $E$. coli J5 (fig. 3B) and LPS of E. coli O111 (fig. 3C). Inhibition by both MAbs was dose-dependent, as shown in fig. 4 for MAb 8-2 against priming with Rc LPS of $E$. coli J5. A control IgM MAb directed against Semliki Forest virus (MAb UM 8.4) did not prevent priming of PMNL with either rough or smooth LPS (fig. 3A-C). The enhanced CL response of PMNL primed with LPS pre-incubated with MAb

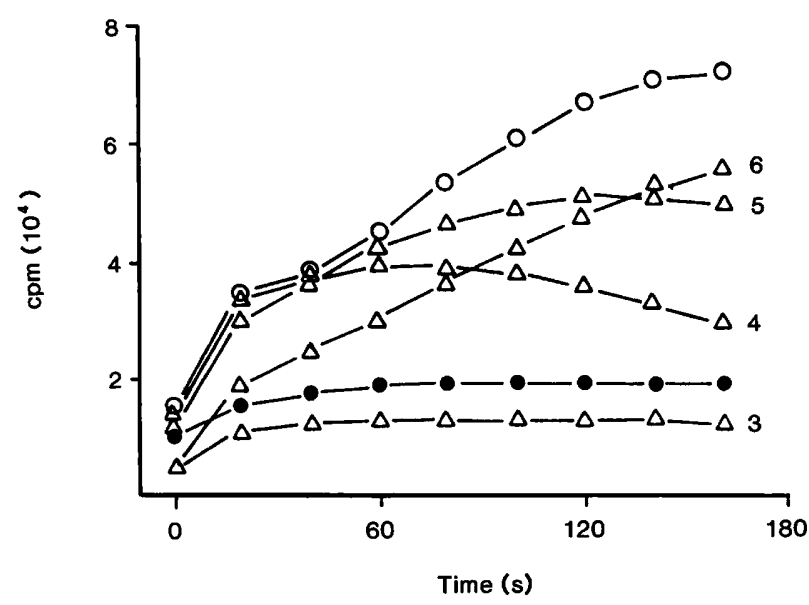

Fig. 2. Inhibition of enhanced $\mathrm{CL}$ response by $\mathrm{PMB}$; $\mathrm{CL}$ response of PMNL primed with pyrogen-free PBS (O), LPS of E. coli J5 (O) and J5 LPS pre-incubated with (3) $10^{-3} \mathrm{mg}$, (4) $10^{-4} \mathrm{mg}$, (5) $10^{-5} \mathrm{mg}$ and $(6) 10^{-6} \mathrm{mg}$ of $\operatorname{PMB}(\triangle)$.
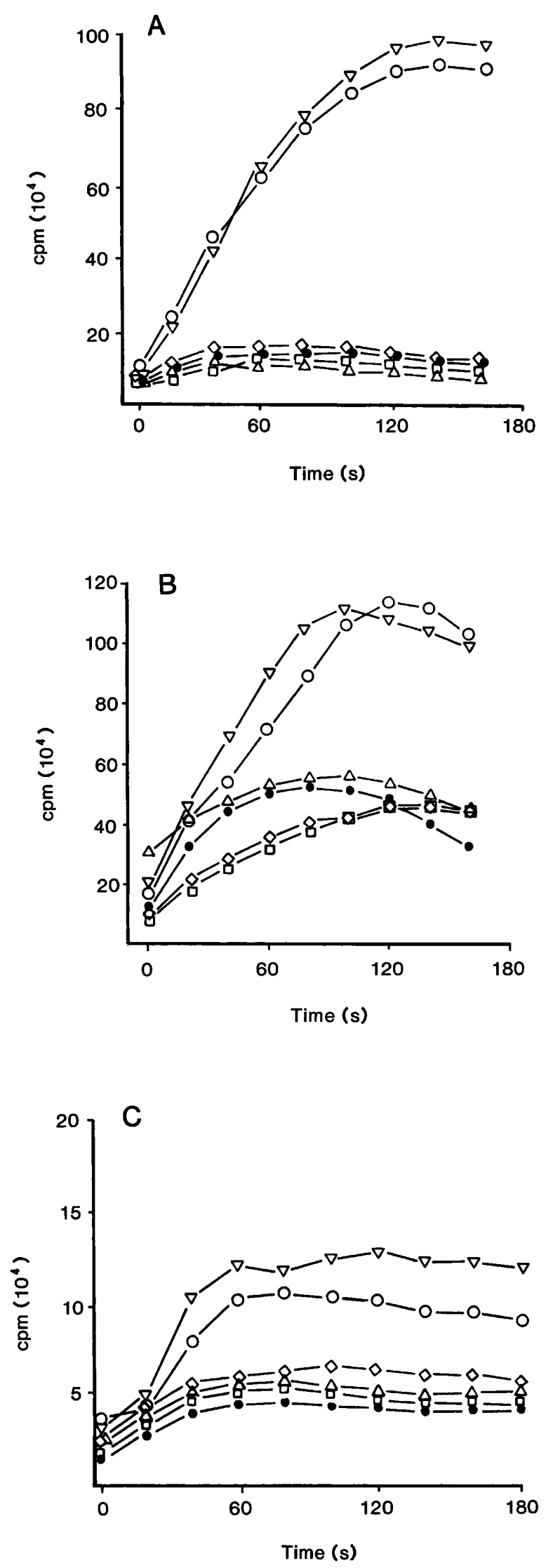

Fig. 3. Inhibition of enhanced CL response by MAb 8-2 or 26-20; CL response of PMNL primed with (A) Re LPS of $S$. minnesota, (B) Rc LPS of $E$. coli J5 or (C) smooth LPS of $E$. coli O111. The LPS preparations were pre-incubated with MAb 8-2 ( $\square$ ), MAb 26-20 $(\diamond)$, control MAb UM 8.4 ( $)$, PMB $(\triangle)$ or pyrogen-free PBS $(O)$; PMNL incubated with pyrogen-free PBS without LPS served as negative control (O). 


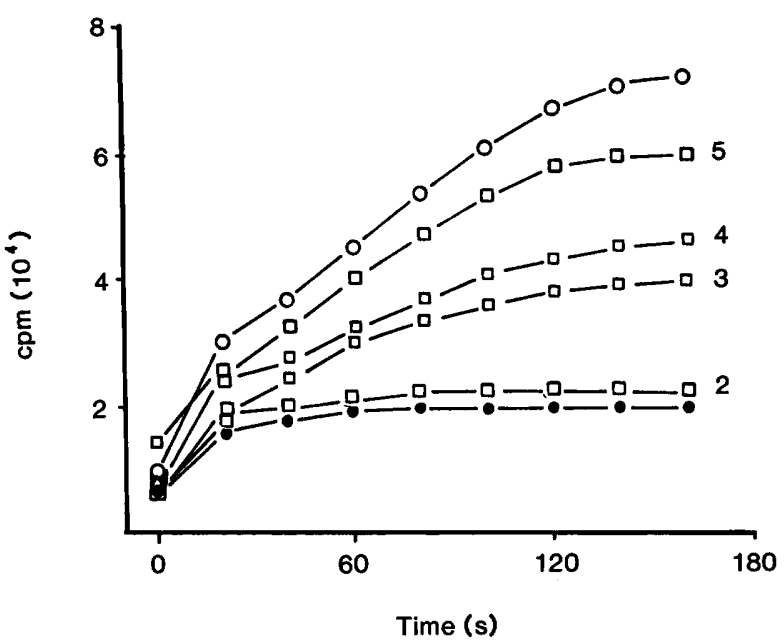

Fig. 4. Inhibition of enhanced $C L$ response by $M A b$ 8-2; CL response of PMNL primed with Rc LPS of $E$. coli $J 5$ pre-incubated with (2) $10^{-2}$, (3) $10^{-3}$, (4) $10^{-4}$ or (5) $10^{-5} \mathrm{mg}$ of MAb 8-2 ( $\square$ ) or pyrogen-free PBS (O) and of PMNL incubated with pyrogen-free PBS without LPS (O).

UM 8.4 equalled the CL response of PMNL primed with LPS pre-incubated with pyrogen-free PBS.

In further experiments to examine whether the abolition of enhanced CL was due to the MAbs acting as scavengers, the MAbs were added after priming of PMNL with LPS, which requires at least $30-60 \mathrm{~min}^{18}$ Subsequent stimulation of PMNL with FMLP produced peak values of $C L$, as high as CL peak values of PMNL primed with LPS and not treated further. The inability of the control IgM MAb UM 8.4 to abolish the enhanced CL response (fig. 3) also argues against a possible scavenging effect.

\section{Discussion}

This study has shown that human PMNL can be primed for an enhanced respiratory burst by exposure to both smooth and rough LPS. The priming of PMNL by LPS was prevented by pre-incubation of LPS with anti-lipid A MAbs. The inhibitory effect of MAbs on LPS was similar to that of the well-known inhibitor PMB.

When PMNL were primed with $100 \mathrm{ng}$ of LPS from $E$. coli J5 (Rc LPS), $1 \mu \mathrm{g}$ of LPS from $E$. coli O111 (smooth LPS) or $100 \mathrm{ng}$ of LPS from $S$. minnesota R595 (Re LPS), stimulation with FMLP caused an enhanced $\mathrm{CL}$ response when compared with untreated cells. Although the LPS dose seems relatively high, when compared with concentrations in vivo, it was needed in order to observe a clear difference between positive and negative controls. As reported earlier, the priming effect varied from donor to donor. ${ }^{13}$ Furthermore, the degree of priming depended on the type of LPS. The CL response after stimulation with FMLP was higher when PMNL were primed with rough LPS. A two-to four-fold increase of CL after stimulation was observed when PMNL were primed with smooth LPS of $E$. coli O111, whereas rough LPS produced a four-to twenty-fold increase. Our findings are consistent with the results of Kapp et al. ${ }^{25}$ and Henricks et al. ${ }^{26}$ who measured CL of PMNL after direct stimulation with LPS. However, the different efficacies of the LPS types on FMLP-induced CL are in contrast with the findings of Fittschen et al., ${ }^{12}$ who showed similar enhancement of PMNL granular secretion for both smooth and rough types of LPS. Kapp et al. ${ }^{25}$ examined 10 types of smooth and rough LPS and showed that the observed difference between rough and smooth LPS was not due to a different degree of aggregation. They suggested that the difference may be due to the more lipophilic character of rough LPS, which may render it more susceptible to interaction with PMNL membranes.

The mechanism by which LPS primes PMNL is still unknown. Lipid $A$ is believed to be primarily responsible for the toxic effects of endotoxin. ${ }^{2}$ It appears that lipid A mediates the binding of LPS to host cells. Many workers have postulated the existence of a specific cell receptor for LPS. ${ }^{27-29}$ Lei and Morrison have isolated a membrane protein from murine splenocytes that binds LPS specifically, ${ }^{29,30}$ but its functional activity remains to be elucidated. Danner et $a l .^{31}$ demonstrated that priming of PMNL can be prevented by lipid $\mathrm{X}$, a precursor of lipid $\mathrm{A}$, and by 3-aza-lipid $\mathbf{X}$, a diamino-analogue of lipid $\mathrm{X}$. The latter molecule also exerted an agonist effect, supporting the possibility of a specific receptor-ligand interaction.

Pre-incubation of rough or smooth LPS with PMB resulted in dose-dependent inhibition of the enhanced CL response of PMNL after FMLP stimulation. PMB is a cyclic polypeptide antibiotic with potent antiendotoxin properties, because it binds to the lipid A part of the LPS molecule. ${ }^{32}$ PMB inhibits priming of PMNL by $R e$ LPS, neutralises the Schwartzman phenomenon, prevents endotoxin lethality in mice and inhibits LPS-induced interleukin-1 secretion. ${ }^{18,33,34}$ Our results support the role of lipid A as the toxic principle of endotoxin responsible for priming of PMNL.

The inhibitory capacity of IgM MAbs 8-2 and 2620 was evaluated and compared with PMB. Both MAbs neutralised the priming effect of the three kinds of LPS tested-Rc LPS of $E$. coli J5, Re LPS of $S$. minnesota R595 and smooth LPS of $E$. coli O111. The protective capacity of both MAbs was dose-dependent and both equalled the maximum inhibitory effect of PMB.

MAbs 26-20 and 8-2 are each specific for a distinct epitope within the hydrophobic lipid A region, ${ }^{11}$ and we have demonstrated previously that the epitopes are obscured after membrane incorporation of lipid $A$ in passive haemolysis and that they are concealed when PMB binds to lipid A in ELISA. ${ }^{10}$ These MAbs may protect PMNL against priming by LPS by preventing the attachment of lipid $A$ to the cell membrane in a similar manner to PMB. The hydrophobic interaction of PMB and endotoxin appears to be necessary for the 
neutralisation of lipid A-mediated effects. ${ }^{31}$ Both MAbs bind to the hydrophobic part of lipid $A$ and may, therefore, mimic the inhibitory activity of PMB. Chia et $a l .{ }^{35}$ reported that MAbs directed against lipid A failed to inhibit LPS-induced secretion of tumour necrosis factor by macrophages. The MAbs described by Chia et al. ${ }^{35}$ and Pollack et al. ${ }^{4}$ reacted predominantly with the hydrophilic elements of lipid A, which could account for the lack of inhibition. Our results emphasise the importance of interaction of MAbs with the hydrophobic part of lipid A.

\section{References}

1. Ryan JL. Microbial factors in pathogenesis: lipopoly-saccharides. In: Root RK, Sande MA (eds) Septic shock (Contemporary issues in infectious diseases, vol 4). New York, Churchill Livingstone. 1985: 13-25.

2. Rietschel ET, Wollenweber H-W, Brade $\mathrm{H}$ et al. Structure and conformation of the lipid A component of lipopolysaccharides. In: Proctor RA (ed) Handbook of endotoxin, vol 1. Amsterdam, Elsevier. 1984: 187-220.

3. Baumgartner JD, O'Brien TX, Kirkland TN, Glauser MP, Ziegler EJ. Demoristration of cross-reactive antibodies to smooth gram-negative bacteria in antiserum to Escherichia coli J5. J Infect Dis 1987; 156: 136-143.

4. Pollack M, Chia JKS, Koles NL, Miller M, Guelde G. Specificity and cross-reactivity of monoclonal antibodies reactive with the core and lipid $A$ regions of bacterial lipopolysaccharide. J Infect Dis 1989; 159: 168-188.

5. Siber GR, Kania SA, Warren HS. Cross-reactivity of rabbit antibodies to lipopolysaccharides of Escherichia coli $\mathrm{J} 5$ and other gram-negative bacteria. J Infect Dis 1985; 152: 954964.

6. Baumgartner J-D, Glauser MP, McCutchan JA et al. Prevention of gram-negative shock and death in surgical patients by antibody to endotoxin core glycolipid. Lancet 1985; 2 : 59-63.

7. McCabe WR, DeMaria A, Berberich H, Johns MA. Immunization with rough mutants of Salmonella minnesota: protective activity of IgM and IgG antibody to the R595 (Re chemotype) mutant. J Infect Dis 1988; 158: 291-300.

8. Ziegler EJ, McCutchan JA, Fierer J et al. Treatment of gramnegative bacteremia and shock with human antiserum to a mutant Escherichia coli. $N$ Engl J Med 1982; 307: 12251230.

9. Calandra T, Glauser MP, Schellekens J, Verhoef $J$ and the Swiss-Dutch J5 Immunoglobulin Study Group. Treatment of gram-negative septic shock with human IgG antibody to Escherichia coli J5: a prospective, double-blind, randomized trial. J Infect Dis 1988; 158: 312-319.

10. Erich T, Schellekens J, Bouter A, van Kranen J, Brouwer E, Verhoef J. Binding characteristics and cross-reactivity of three different antilipid A monoclonal antibodies. $J$ Immunol 1989; 143: 4053-4060.

11. Cornelissen JJ, Oosterlaken TAM, Schellekens J et al. Discrimination by rabbit anti-idiotypic antibodies of two murine IgM monoclonal antibodies directed against lipid A. $J$ Immunol Methods 1990; 130: 141-147.

12. Fittschen C, Sandhaus RA, Worthen GS, Henson PM. Bacterial lipopolysaccharide enhances chemoattractant-induced elastase secretion by human neutrophils. J Leukoc Biol $1988 ; 43$ : 547-556.

13. Guthrie LA, McPhail LC, Henson PM, Johnston RB. Priming of neutrophils for enhanced release of oxygen metabolites by bacterial lipopolysaccharide. Evidence for increased activity of the superoxide-producing enzyme. $J$ Exp Med 1984; 160 : 1656-1671.

14. Haslett C, Guthrie LA, Kopaniak MM, Johnston RB, Henson PM. Modulation of multiple neutrophil functions by preparative methods or trace concentrations of bacterial lipopolysaccharide. Am J Pathol 1985; 119: 101-110.
In conclusion, two IgM MAbs, 8-2 and 26-20, directed against separate epitopes within the hydrophobic lipid A part of LPS, inhibited the enhanced CL response of PMNL primed with different forms of LPS. Their protective capacity was as potent as the inhibition produced by PMB. Although data from in vitro studies cannot be translated to the in-vivo situation, these results indicate that in-vivo protection experiments are worthy of further investigation.
15. Briheim G, Stendahl O, Dahlgren C. Intra- and extra-cellular events in luminol-dependent chemiluminescence of polymorphonuclear leukocytes. Infect Immun 1984; 45: 1-5.

16. Bass DA, Olbrantz P, Szejda P, Seeds MC, McCall CE. Subpopulations of neutrophils with increased oxidative product formation in blood of patients with infection. $J$ Immunol 1986; 136: 860-866.

17. Brigham KL, Bowers RE, Haynes J. Increased sheep lung vascular permeability caused by Escherichia coli endotoxin. Circ Res 1982; 45: 292-297.

18. Craig WA, Turner JH, Kunin CM. Prevention of the generalized Shwartzman reaction and endotoxin lethality by polymyxin B localized in tissues. Infect Immun 1974; 10: $287-292$.

19. Galanos C, LüderitzO, Rietschel ET, Westphal O. Biochemistry of lipids 11. Int Rev Biochem 1977; 14: 290-292.

20. Westphal $O$, Lüderitz $O$, Bister $F$. Uber die Extraktion von Bakterien mit Phenol/Wasser. Z Naturforsch 1952; Teil B 7: 148-155.

21. Boere WAM, Harmsen T, Vinjé J, Benaissa-Trouw BJ, Kraaijeveld CA, Snippe H. Identification of distinct antigenic determinants on Semliki Forest virus by using monoclonal antibodies with different antiviral activities. $J$ Virol 1984; 52: 575-582.

22. Chen FM, Naeve GS, Epstein AL. Comparison of mono Q, superose-6, and $\mathbf{A B x}$ fast protein liquid chromatography for the purification of IgM monoclonal antibodies. $J$ Chromatogr 1988; 444: 153-164.

23. Lowry OH, Rosebrough NJ, Farr AL, Randall RJ. Protein measurement with the Folin phenol reagent. J Biol Chem 1951; 193: 265-75.

24. Remillard JF, Gould MC, Roslansky PF, Novitsky TJ. Quantitation of endotoxin in products using the LAL kinetic turbidimetric assay. In: Watson SW, Lewin J, Novitsky TJ (eds) Detection of bacterial endotoxins with the limulus amebocyte lysate test. (Progress in clinical and biological research, vol 231.) New York, A. R. Liss. 1987: 197-210.

25. Kapp A, Freudenberg M, Galanos C. Induction of human granulocyte chemiluminescence by bacterial lipopolysaccharides. Infect Immun 1987; 55: 758-761.

26. Henricks PAJ, Van der Tol ME, Thyssen RMWM, van Asbeck S, Verhoef J. Escherichia coli lipopolysaccharides diminish and enhance cell function of human polymorphonuclear leukocytes. Infect Immun 1983; 41: 294-301.

27. Haeffner-Cavaillon N, Chaby R, Cavaillon J-M, Szabó L Lipopolysaccharide receptor on rabbit peritoneal macrophages. I. Binding characteristics. J Immunol 1982; 128: 1950-1954.

28. Hampton RY, Golenbock DT, Raetz CRH. Lipid A binding sites in membranes of macrophage tumor cells. $J$ Biol Chem 1988; 263: 14802-14807.

29. Lei M-G, Morrison DC. Specific lipopolysaccharide-binding proteins on murine splenocytes. I. Detection of lipopolysaccharide-binding sites on splenocytes and splenocyte subpopulations. J Immunol 1988; 141 : 996-1005.

30. Lei M-G, Morrison DC. Specific endotoxic lipopolysaccharidebinding proteins on murine splenocytes. II. Membrane localization and binding characteristics. J Immunol 1988; 141: 1006-1011. 
31. Danner RL, Joiner KA, Parrillo JE. Inhibition of endotoxininduced priming of human neutrophils by lipid $X$ and 3Aza-lipid X. J Clin Invest 1987; 80: 605-612.

32. Morrison DC, Jacobs DM. Binding of polymyxin B to the lipid A portion of bacterial polysaccharides. Immunochem 1976; 13: 813-818.

33. Cavaillon J-M, Haeffner-Cavaillon N. Polymyxin-B inhibition of LPS-induced interleukin-1 secretion by human monocytes is dependent upon the LPS origin. Mol Immunol 1986; 23: 965-969.
34. Danner RL, Joiner KA, Rubin $\mathbf{M}$ et al. Purification, toxicity, and antiendotoxin activity of polymyxin B nonapeptide. Antimicrob Agents Chemother 1989; 33: 1428-1434.

35. Chia JKS, Pollack M, Guelde G, Koles NL, Miller M, Evans ME. Lipopolysaccharide (LPS)-reactive monoclonal antibodies fail to inhibit LPS-induced tumor necrosis factor secretion by mouse-derived macrophages. J Infect Dis $1989 ; 159: 872-880$. 